\title{
A EMERGÊNCIA DA RESPONSABILIDADE CRIMINAL INDIVIDUAL NO SISTEMA INTERAMERICANO DE DIREITOS HUMANOS*
}

Raquel da Cruz Lima

Este artigo tem como inspiração as pesquisas de Kathryn Sikkink sobre justiça de transição, em especial as conclusões reunidas no livro The Justice Cascade. Nesta obra, Sikkink reconstrói a emergência da norma relativa à responsabilidade criminal individual de agentes estatais que cometeram graves violações de direitos humanos e a maneira como essa norma se difundiu. De especial interesse para nosso trabalho é a premissa de Sikkink de que por muito tempo a responsabilidade criminal individual não era considerada, tanto pelas vítimas das violações quanto por ONGs, como uma medida aplicável a agentes estatais responsáveis por essas violações, em especial no contexto de transição de regimes autoritários para democráticos. Assim, a desnaturalização do recurso à persecução penal como uma medida que compõe o repertório de instrumentos do direito internacional dos direitos humanos, tal

\footnotetext{
* Este artigo está ligado à dissertação de mestrado O direito penal dos direitos humanos: paradoxos no discurso punitivo da Corte Interamericana de Direitos Humanos, financiada pela Fapesp.
} 
qual encarado por Sikkink (2011), é base fundamental deste $\operatorname{artigo}^{1}$.

Partindo desse pressuposto, será mostrado como no Sistema Interamericano de Direitos Humanos (SIDH), em especial na jurisprudência contenciosa da Corte Interamericana $(\mathrm{CtIDH})$, vem se desenvolvendo a norma da responsabilidade criminal individual, e também como a referência a esta deixou de se limitar a casos de transição democrática - que são os tratados por Sikkink - para se expandir para o tratamento de outros casos. Naturalmente, a exposição do desenvolvimento da norma da responsabilidade criminal individual não seguirá neste artigo o método de The Justice Cascade de acompanhar os diversos agentes empreendedores da norma na sua difusão. Em função das proporções deste texto, nos restringiremos a observar como dentro da própria jurisprudência da CtIDH ocorre a incorporação e difusão da norma da responsabilidade 188 criminal individual. Justifica-se o enfoque no desenvolvimento dessa nova norma no âmbito do SIDH por conta da importância que os órgãos regionais de direitos humanos tiveram para o início de processos domésticos de persecução criminal nas Américas, com destaque para o pioneiro caso da Argentina ${ }^{2}$.

A organização deste artigo seguirá a seguinte estrutura: primeiramente serão expostos os principais argumentos que compõem o livro The Justice Cascade e que dialogam

\footnotetext{
${ }^{1}$ Não se quer com isso sugerir que a persecução criminal individual seja uma medida livre de polêmica, sobretudo nos casos de transição democrática. Ocorre que concordamos com Sikkink de que está em curso um processo de difusão desta norma a ponto de, hoje, entre diversos militantes de direitos humanos, ela ser pensada como uma bandeira natural.

${ }^{2}$ Segundo Sikkink, a Comissão Interamericana de Direitos Humanos foi a primeira entidade a pautar na Argentina a necessidade de processos judiciais apurarem as violações de direitos humanos ocorridas. Naturalmente, os grupos argentinos de direitos humanos já desejavam a realização de alguma forma de justiça, mas a posição de uma organização internacional respeitada foi fundamental para a consideração de que sua demanda poderia ser concretizada (2011, p.66-7).
} 
mais diretamente com a jurisprudência da CtIDH; em seguida, abordaremos o tratamento do SIDH à norma de responsabilidade criminal individual, considerando, inicialmente, os casos de leis de anistia em transições democráticas e, em seguida, a difusão dessa norma para casos de temáticas diversas; enquanto a última parte consiste na indicação de algumas críticas que podem surgir para a norma de responsabilização criminal individual, na medida em que ela sofre modificações na jurisprudência da CtIDH.

\section{Cascata de justiça}

Entre as preocupações centrais de Sikkink no livro está o impressionante crescimento dos processos de direitos humanos ${ }^{3}$, inseridos no contexto de crescente accountability na política mundial que ela e Ellen Lutz chamaram de cascata de justiça (Lutz; Sikkink, 2001). Sikkink acredita que esta é uma tendência que não fora antecipada nem explicada pela ciência política e que vem a romper a "ortodoxia reinante" sobre soberania estatal e imunidade de chefes de Estado. Aliás, esta incapacidade das teorias de relações internacionais explicarem a ruptura que a persecução criminal de chefes de Estado representa é o que leva Sikkink a concluir que as principais ferramentas utilizadas pelos cientistas políticos servem melhor à explicação da continuidade do que da mudança.

Mas o principal problema não seria o de desenvolver uma teoria de relações internacionais que explique satisfatoriamente mudanças, mas o de conseguir provar que existe uma mudança específica em curso: a emergência de

\footnotetext{
${ }^{3}$ Estes processos de direitos humanos são ações judiciais baseadas em três elementos: (i) as mais graves violações de direitos humanos não podem ser vistas como atos legítimos dos Estados, mas devem ser vistos como crimes cometidos por indivíduos; (ii) os indivíduos que cometem esses crimes devem ser processados; (iii) os acusados são sujeitos de direito e devem gozar das garantias do devido processo (Sikkink, 2011, p.12-3).
} 
uma nova norma nos processos de transição democrática estatuindo a responsabilidade criminal individual de agentes estatais responsáveis por violações de direitos humanos. Com isso, não se pretende afirmar que todos os chefes de Estado que violem normas de direitos humanos serão mandados para a prisão, mas sim que existiria uma crescente força e legitimidade na norma sustentando que a conduta de agentes estatais violatória a direitos humanos deve ser apurada (Sikkink, 2011, p.11-2). Por acreditar que muitos dos céticos sobre os processos de direitos humanos não estão munidos de evidências empíricas suficientes para sustentar suas posições, as duas primeiras partes de The Justice Cascade mostram as fontes e origens da responsabilidade criminal individual por violações de direitos humanos e também sugerem como essas novas ideias de accountability se difundiram.

Um dos grandes méritos do livro em relação a outros 190 trabalhos que mostram o aparecimento da faceta criminal do direito internacional é que ele não se limita a identificar esse processo como uma evolução linear do Tribunal de Nuremberg até a criação do Tribunal Penal Internacional, intermediados por tribunais penais ad hoc. Nele, essa genealogia dos tribunais internacionais é apenas uma das dimensões do desenvolvimento da norma, que paralelamente viu a ocorrência de casos de persecuções criminais domésticas, notadamente os da Grécia, Portugal e Argentina.

É fundamental destacar que, para Sikkink, a emergência e difusão dessa nova norma não foi um movimento espontâneo e que ocorreu de forma passiva, como que uma doença contagiosa, mas o resultado da ação de movimentos de direitos humanos, redes de advocacy, comunidades epistêmicas e redes transnacionais entre países com interesses comuns, que operaram dentro de uma estrutura favorável: a terceira onda de democracia e o fim da guerra fria (2011, p.19, 23). Como a negação da passividade na difusão da nor- 
ma já sugeriria, Sikkink dá grande destaque para o papel da agência humana e por isso narra, principalmente por meio de dados reunidos a partir de entrevistas, como indivíduos específicos ajudaram a conceber a estratégia de persecução criminal dos agentes estatais e depois difundiram suas experiências para outros países e em redes transnacionais ${ }^{4}$.

É pressuposto do livro que é adequado responsabilizar criminal e individualmente os agentes estatais por violações ocorridas no passado, até por razões subjetivas de justiça, como o instinto humano profundo de que alguns direitos não podem ser violados e que, ocorrendo violação, seus responsáveis devem ser punidos (Sikkink, 2011, p.255, 261). Todavia, na condição de uma cientista política, ela acredita que o seu papel não seja o mesmo de um filósofo moral que se pergunta se é certo ou errado realizar esses julgamentos, mas sim o de avaliar as consequências empíricas destes e se realmente promovem o respeito aos direitos humanos (Sikkink, 2011, p.229). Por isso, a terceira parte do livro tem como objetivo avaliar os impactos desses julgamentos e confrontar seus dados com algumas correntes da ciência política.

Sikkink admite que exista controvérsia sobre a correção de seu método para catalogar os dados relativos aos processos de responsabilização e que é possível que não tenha conseguido identificar todos os fatores influentes no cenário de análise. Mesmo assim, as seguintes conclusões, e que já apareciam em obras anteriores (Sikkink; Walling, 2010), são apresentadas como tendo sólido respaldo empírico: (i) não é possível afirmar que os julgamentos prejudicam a democracia; (ii) a escolha pela responsabilização criminal não é excludente nem precisa ser feita no momento da transição; (iii) comissões de verdade e julgamentos de

\footnotetext{
${ }^{4} \mathrm{O}$ início de qualquer cascata normativa estaria no trabalho intenso de determinados indivíduos na propositura e divulgação de novas ideias, as quais seriam compartilhadas com outras pessoas e atingiriam novos cenários. (Sikkink, 2011, p.23).
} 
direitos humanos não são opções incompatíveis e (iv) não é possível afirmar que os processos criminais deteriorem a situação dos direitos humanos.

Estando expostos os principais pontos do livro The Justice Cascade, passaremos a avaliar a difusão da regra da responsabilidade criminal individual dentro do SIDH.

\section{A emergência da norma de responsabilidade criminal individual no Sistema Interamericano de Direitos Humanos}

\section{O Sistema Interamericano e o paradigma da responsabilidade estatal}

$\mathrm{O} \mathrm{SIDH}$ é ligado à Organização dos Estados Americanos (OEA), hoje composto por dois órgãos: a Comissão Interamericana de Direitos Humanos (CIDH) e a Corte Interamericana de Direitos Humanos. Apesar de alguma preocupa-

192 ção com a temática dos direitos humanos já estar presente desde a criação da OEA, em 1948, como atesta a aprovação a Declaração Americana de Deveres e Direitos do Homem, somente em 1959 que foi criada a CIDH, com a função de promover os direitos humanos nas Américas (Pasqualucci, 2003).

O documento que confere o atual desenho institucional do SIDH é a Convenção Americana sobre Direitos Humanos $(\mathrm{CADH})$, de 1969, considerada a mais ambiciosa das convenções existentes sobre o tema - muitas de suas garantias são mais abrangentes do que as previstas na Convenção Europeia para a Proteção dos Direitos Humanos e Liberdades Fundamentais ou no Pacto Internacional de Direitos Civis e Políticos - e que, até por isso, desde sua elaboração, teve questionada a sua capacidade de ser plenamente respeitada por algum Estado (Hanashiro, 2001, p.32). Mais do que simplesmente arrolar direitos e garantias - como fizera a Declaração Americana de Deveres e Direitos do Homem 
-, a CADH estabeleceu a obrigação de os Estados-partes respeitarem os direitos nela previstos ${ }^{5}$ e adotarem medidas de direito interno a fim de torná-los efetivos ${ }^{6}$. Como será discutido adiante, são essas duas previsões que ofereceram o substrato jurídico para as considerações da CtIDH sobre a responsabilidade criminal individual.

Para monitorar o cumprimento dessas obrigações, a CADH atribuiu competência a dois órgãos: à já existente CIDH e à CtIDH. Com a criação desta última, o SIDH passou a contar com um órgão competente não só para interpretar a CADH e quaisquer outros tratados internacionais de direitos humanos por meio de sua jurisdição consultiva $^{7}$, mas também para decidir demandas individuais referentes a violações de direitos previstos nessa convenção ${ }^{8}$. Assim, para aqueles Estados que a ratificassem e aceitassem a cláusula de jurisdição facultativa obrigatória ${ }^{9}$,

\footnotetext{
5 “Artigo 1. Obrigação de respeitar os direitos. 1. Os Estados-partes nesta Convenção comprometem-se a respeitar os direitos e liberdades nela reconhecidos e a garantir seu livre e pleno exercício a toda pessoa que esteja sujeita à sua jurisdição, sem discriminação alguma por motivo de raça, cor, sexo, idioma, religião, opiniões políticas ou de qualquer outra natureza, origem nacional ou social, posição econômica, nascimento ou qualquer outra condição social".

6 "Artigo 2. Dever de adotar disposições de direito interno. Se o exercício dos direitos e liberdades mencionados no artigo 1 ainda não estiver garantido por disposições legislativas ou de outra natureza, os Estados-partes comprometem-se a adotar, de acordo com as suas normas constitucionais e com as disposições desta Convenção, as medidas legislativas ou de outra natureza que forem necessárias para tornar efetivos tais direitos e liberdades".

${ }^{7}$ Como consagrou a primeira opinião consultiva emitida pela CtIDH, a CADH a atribui competência para interpretar qualquer tratado relativo a direitos humanos, ainda que não tenha sido celebrado no âmbito regional (CtIDH, 1982). Com isso, pode-se afirmar que a competência consultiva da CtIDH é a mais ampla entre os tribunais de direitos humanos.

${ }^{8}$ Com o desenvolvimento do SIDH, a CtIDH passou a ter competência contenciosa sobre dispositivos de outros tratados, como o artigo $7^{\circ}$. da Convenção de Belém do Pará e a alínea "a" do artigo $8^{\circ}$. (a) e o $13^{\circ}$. do Protocolo de San Salvador.

${ }^{9}$ Os Estados que ratificaram a CADH são: Argentina, Barbados, Bolívia, Brasil, Colômbia, Costa Rica, Chile, Dominica, Equador, El Salvador, Granada, Guatemala, Haiti, Honduras, Jamaica, México, Nicarágua, Panamá, Paraguai, Peru, República Dominicana, Suriname, Trindade e Tobago, Uruguai e Venezuela. Contudo, em 1998, Trindade e Tobago denunciou a CADH. De todos estes, apenas Granada e Jamaica não reconhecem a jurisdição da CtIDH.
} 
o SIDH passou a contar com um mecanismo de implementação de tratados de direitos humanos que até então só havia na Europa e que criava a possibilidade de se aplicar a CADH a casos individuais, estabelecendo obrigações jurídicas vinculantes ao Estado.

Corroborando um argumento de Sikkink sobre como entender, na perspectiva do interesse dos atores, que os Estados tenham ratificado tratados de direitos humanos gerando uma estrutura propícia para a cascata de justiça -, observa-se que a criação da CtIDH ocorreu por meio da ratificação de um tratado de direitos humanos por Estados não democráticos e que não tinham clareza quanto aos custos envolvidos nessa ação, sendo vítimas, portanto, de verdadeira autoarmadilha (Sikkink, 2011, p.239). Prova disso está no fato de a instalação da CtIDH ter ocorrido como que por acidente, quando o governo de Granada inadvertidamente depositou o $11^{\circ}$ instrumento de ratifica-

194 ção, alheio ao fato de que, com isso, se estava instaurando o órgão (Hanashiro, 2001, p.43) ${ }^{10}$.

O modelo de promoção de direitos humanos que criou o SIDH é aquele que busca responder ao choque dos eventos ligados à Segunda Guerra Mundial, atribuindo aos indivíduos direitos que criavam barreiras ao arbítrio dos agentes estatais até então protegidos pelo manto da soberania. A partir da redação da Declaração Universal de Direitos Humanos e dos demais tratados de direitos humanos subsequentes, criou-se um modelo de responsabilização em que o Estado como um todo respondia pelas violações de direitos humanos ocorridas e tinha a obrigação de remediá-las ${ }^{11}$.

\footnotetext{
${ }^{10} \mathrm{O}$ início das atividades da CtIDH não era imediato quando da entrada em vigor da $\mathrm{CADH}$, mas dependia da ratificação de no mínimo 11 Estados.

${ }^{11}$ Nenhum dos primeiros core treaties do direito internacional dos direitos humanos fala diretamente em um dever de os Estados punirem criminalmente indivíduos que violem direitos humanos.
} 
O modelo de responsabilidade estatal consagrado depois da Segunda Guerra Mundial estabelece que a responsabilidade do Estado não depende nem implica na dos indivíduos (Nollkaemper, 2003, p.616). Bom exemplo desse modelo é o caso Selmouni vs. França julgado em 1999 pela Corte Europeia de Direitos Humanos (CtEDH), em que se considerou a França responsável por tortura (entre outras violações), ainda que procedimentos criminais domésticos estivessem sendo utilizados para sancionar o policial diretamente responsável pela prática (CtEDH, 1999). Para Sikkink, o modelo de responsabilidade estatal difundido por todo o aparato de direitos humanos da ONU caminha lado a lado com a ideia de que agentes estatais estão imunes de persecução por violações de direitos humanos (2011, p.14).

Entre as maneiras utilizadas pela CtIDH para ressaltar que a responsabilidade por violações de direitos humanos considera o Estado como um todo estão a recusa em aceitar a organização federativa como causa de descumprimento de obrigações internacionais e doutrinas como a da devida diligência, que justificam a responsabilidade estatal mesmo nos casos em que a violação de direitos humanos foi cometida por particulares (Garcia Elorrio, 2011; Dulitzky, 2006). A desvinculação entre o modelo internacional de responsabilidade e a identificação e sanção dos indivíduos responsáveis pelo cometimento das violações apareceu nas considerações da CtIDH na primeira sentença de mérito prolatada, como se lê no parágrafo 134 desta:

a proteção internacional dos direitos humanos não deve ser confundida com justiça penal. Os Estados não se colocam perante a Corte como sujeitos de uma ação penal. O direito internacional dos direitos humanos não tem como desígnio impor penas às pessoas culpadas pelas violações, mas amparar as vítimas e oferecer a reparação dos danos que 
lhes tenham sido causados pelos Estados responsáveis por tais ações (CtIDH, 1988).

Essa sentença mostra a autoafirmação da CtIDH de que o recebimento de casos individuais no âmbito regional não funcionaria como uma justiça penal e que o agente ao qual ela se dirige para estabelecer obrigações decorrentes do descumprimento das obrigações internacionais é, unicamente, o Estado. Contudo, como mostra Sikkink, há um novo modelo de responsabilidade por violações de direitos humanos em desenvolvimento. A maneira como esse modelo aparece na CtIDH é o que será explorado as seguir.

\section{Justiça e verdade: a proibição de anistias para violações de direitos humanos}

Os primeiros anos de atividade do SIDH já organizado a partir da $\mathrm{CADH}$ coincidiram com o contexto de sistemá-

196 ticas e massivas violações de direitos humanos ligadas a terrorismo de Estado ou a violentos conflitos armados internos. Mesmo nos momentos em que os membros da CIDH não estavam ligados aos regimes militares ${ }^{12}$, a asfixia política no interior dos Estados tornava até inadequada a submissão de casos individuais à comissão, dado que os Estados não participavam de forma alguma da litigância, nem mesmo indicando provas para negar os fatos narrados. Aliado a esse fator, o caráter sistemático das violações cometidas e a necessidade de confrontá-las de forma mais coletiva também levaram a CIDH a adotar os informes como principal instrumento para a proteção dos direitos humanos. Na preparação de seus relatórios, a CIDH utilizava extensivamente visitas in loco que contribuíam para chamar atenção da opinião pública, aumentar a visibilidade das vítimas e expor o Estado no

\footnotetext{
${ }^{12}$ Já que por muito tempo a OEA foi considerada um "clube de cavalheiros anticomunistas" (Sikkink, 2011, p.64).
} 
âmbito internacional, ainda que sem atribuir responsabilidade pelas violações ou sem poder exigir medidas de compensação para as vítimas (González, 2010, p.106).

Entre as décadas de 1980 e 1990, no período de transição pós-ditatorial, os órgãos do SIDH passaram a acompanhar e monitorar os processos políticos de tratamento do passado autoritário, mas ainda dando primazia para mecanismos que não confrontavam as práticas estatais diretamente. Nesse sentido devem ser entendidas as primeiras opiniões consultivas do órgão, que protegeram a liberdade de imprensa (CtIDH, 1985, 1986), o habeas corpus (CtIDH, 1987a) e as garantias judiciais (CtIDH, 1987b), levando ao desenvolvimento de uma doutrina básica sobre a relação entre direitos humanos, garantias processuais, Estado de direito e democracia ${ }^{13}$.

$\mathrm{O}$ recebimento pela CtIDH de seus primeiros casos contenciosos coincidiu com o início do processo de redemocratização da América Latina, no final dos anos de 1980. As primeiras alegações de violações à $\mathrm{CADH}$ com as quais a CtIDH se confrontou diziam respeito a crimes cometidos em um contexto ditatorial (principalmente desaparecimentos forçados e execuções extrajudiciais), em que muitas das violações estavam associadas à existência de um sistema nacional de justiça devastado ou corrupto (Abramovich, 2009, p.9). Assim, no julgamento desses primeiros casos contenciosos que a julgou, ela relacionou a obrigação de os Estados garantirem o cumprimento do parágrafo 1ำ do artigo 1ำ da CADH à organização de um sistema de justiça efetivo, capaz de investigar e sancionar as violações de direi-

\footnotetext{
${ }^{13}$ Deve-se observar que o predomínio da jurisdição consultiva em relação à contenciosa nos primeiros anos de atividade da CtIDH foi motivo de preocupação para alguns acadêmicos, que viam nessa situação um possível de fragilização da $\mathrm{CADH}$ já que mesmo diante de inúmeros casos de graves violações os Estados não eram responsabilizados internacionalmente e não se garantia a eficácia do texto pactuado (Hanashiro, 2001, p.57).
} 
tos humanos ocorridas em seu território. É o que aparece no trecho abaixo:

a segunda obrigação [em relação ao disposto no parágrafo 1 do artigo 1ำ da CADH] dos Estados Partes é a de garantir o livre e pleno exercício dos direitos reconhecidos na Convenção a toda pessoa sob sua jurisdição. Esta obrigação implica o dever de os Estados Partes organizarem todo o aparato governamental e, em geral, todas as estruturas pelas quais se manifesta o exercício do poder público, de tal maneira que sejam capazes de assegurar juridicamente o livre e pleno exercício dos direitos humanos. Como consequencia desta obrigação, os Estados devem prevenir, investigar e sancionar toda violação dos direitos reconhecidos na Convenção e procurar, ademais, restaurar o direito violado e, se necessário, reparar os danos causados pela violação dos direitos humanos. (CtIDH, 1988, grifo nosso).

Assim, na interpretação do parágrafo $1^{\circ}$ do artigo $1^{\circ}$, começava a ser desenvolvida a doutrina sobre o dever de os Estados investigarem e sancionarem os responsáveis por violações a direitos protegidos na $\mathrm{CADH}$. Naquele momento de desenvolvimento jurisprudencial, o dever de investigar estava muito associado aos casos de desaparecimentos for$\operatorname{çados}^{14}$, em que era justamente a falta de investigação que levava à configuração da violação da $\mathrm{CADH}$ e da responsabilidade internacional.

Casos como "Suarez Rosero" e "Niños de la Calle" voltaram a insistir na importância da obrigação de investigar e punir como medida de efetivação dos direitos previstos na $\mathrm{CADH}$. Enquanto no Caso Saurez Rosaro se estabele-

\footnotetext{
${ }^{14}$ Como nos três primeiros casos hondurenhos (CtIDH, 1988, 1989a, 1989b). O desaparecimento forçado se caracteriza pela incerteza sobre o destino da pessoa, que por sua vez é causada exatamente pela ausência de investigação, ver o parágrafo 34 de CtIDH (1989).
} 
ceu que, como medida de reparação, o Equador deveria "ordenar uma investigação para identificar e, eventualmente, sancionar as pessoas responsáveis pelas violações aos direitos humanos a que esta sentença fez referência" (CtIDH, 1997b), a sentença do Caso Niños de la Calle destacou a relação entre a obrigação de punir e o direito a um recurso efetivo e à proteção judicial. Segundo a CtI$\mathrm{DH}$, o artigo 25 da $\mathrm{CADH}^{15}$ foi violado pela Guatemala na medida em que as autoridades competentes deixaram de realizar diversas tarefas de investigação decisivas para identificar os responsáveis pelo assassinato dos meninos Henry Giovanni Contreras, Federico Clemente Figueroa Túnchez, Julio Roberto Caal Sandoval, Jovito Josué Juárez Cifuentes e Anstraum Aman Villagrán Morales na Cidade da Guatemala em um contexto de execuções extrajudiciais contra meninos em situação de rua perpetradas por agentes de segurança ${ }^{16}$. Isso porque, conforme o parágrafo 226 da mesma sentença,

a obrigação de investigar deve ser cumprida com seriedade e não como uma simples formalidade fadada de antemão a ser mal sucedida. Deve ter o sentido e ser assumida pelo Estado como um dever jurídico próprio e não como uma simples gestão de interesses particulares, dependente da iniciativa processual da vítima ou de seus familiares, ou do oferecimento privado de elementos probatórios, sem que a

\footnotetext{
15 “Artigo 25. Proteção judicial. 1. Toda pessoa tem direito a um recurso simples e rápido ou a qualquer outro recurso efetivo, perante os juízes ou tribunais competentes, que a proteja contra atos que violem seus direitos fundamentais reconhecidos pela constituição, pela lei ou pela presente Convenção, mesmo quando tal violação seja cometida por pessoas que estejam atuando no exercício de suas funções oficiais. 2. Os Estados-parte comprometem-se: a) a assegurar que a autoridade competente prevista pelo sistema legal do Estado decida sobre os direitos de toda pessoa que interpuser tal recurso; b) a desenvolver as possibilidades de recurso judicial e c) a assegurar o cumprimento, pelas autoridades competentes, de toda decisão em que se tenha considerado procedente o recurso".

${ }^{16}$ Ver parágrafos 199 e 200 de CtIDH (1999).
} 
autoridade pública efetivamente busque a verdade (CtIDH, 1999, grifos nossos).

Além disso, tendo havido suspostos responsáveis pelos crimes que foram absolvidos judicialmente, a CtIDH passa a mostrar que também a impunidade é ofensiva aos direitos humanos, conforme lê-se no parágrafo 228:

É evidente que os responsáveis por tais fatos estão impunes, porque não foram identificados nem sancionados mediante atos judiciais que tenham sido executados. Esta única consideração é suficiente para concluir que o Estado violou o artigo 1.1 da Convenção, pois não puniu os autores dos delitos em questão. A este respeito, não cabe discutir se as pessoas acusadas nos processos internos deviam ou não ser absolvidas. O importante é que, independentemente de terem sido ou não elas as responsáveis pelos ilíticos, o Estado devia identificar e punir aquelas que realmente o fossem, e não o fez. (CtIDH, 1999, grifos nossos).

A preocupação com o combate à impunidade já aparecera em um caso anterior, "Paniagua Morales", também contra a Guatemala, e que envolvia a prática de detenções arbitrárias, sequestros, torturas e assassinatos, o parágrafo 173 da sentença de mérito afirma:

A Corte constata que na Guatemala existia e existe uma situação de impunidade relativa aos fatos do presente caso, entendendo-se como impunidade a falta conjunta de investigação, persecução, prisão, julgamento e condenação dos responsáveis pelas violações dos direitos protegidos pela Convenção Americana, pois o Estado tem a obrigação de combater tal situação por todos os meios legais disponíveis, já que a impunidade propicia a repetição crônica das violações 
de direitos humanos e a total desproteção das vítimas e de seus familiares (CtIDH, 1998 grifos nossos).

Esses casos julgados nos primeiros anos de funcionamento da CtIDH mostram que a responsabilidade criminal do indivíduo apareceu como uma obrigação estatal ligada à implementação doméstica da CADH e que, portanto, a sua ausência fundamentava a responsabilidade internacional do Estado. Além disso, a impunidade era vista como causa da repetição das violações de direitos humanos e também como uma barreira para o conhecimento da verdade, sobretudo no caso de um crime que se define pela falta de acesso à informação: o desaparecimento forçado. Mas é preciso atentar que a falta de persecução criminal que a CtIDH critica nesses casos está ligada à leniência ou à fragilidade de sistemas de justiça, e não a obstáculos institucionais deliberadamente implementados para impedir a responsabilização criminal individual nos casos de violações de direitos humanos por regimes autoritários.

Com a chegada dos anos de 1990 e o crescente papel do SIDH no monitoramento dos processos políticos nacionais que lidavam com a superação de regimes autoritários, o dever de investigar e punir foi se tornando uma referência consolidada nos pronunciamentos da CtIDH, que não mais tinha como foco apenas as fragilidades aos sistemas nacionais de justiça, mas o próprio regime democrático.

Naquele contexto, o Caso Barrios Altos vs. Peru (CtIDH, 2001) tornou-se um paradigma porque afirmou a invalidade das leis de anistia que perdoassem graves violações de direitos humanos. O nome desse caso é uma referência ao bairro de Lima onde ocorreu, no dia 3 de novembro de 1991, a invasão de uma festa e o subsequente assassinato de quinze pessoas, que ainda deixou outras quatro gravemente feridas. Inserido na lógica de combate a "subversivos" que marcava a forma de "estabilização da democracia" do Peru de 
Fujimori, foi posteriormente identificado que esse massacre fazia parte de uma série de práticas estatais de extermínio conduzidas por membros do Exército peruano. Todavia, a aprovação de duas leis de anistia em 1995 (Leis 26.479 e 26.492) ${ }^{17}$ impediram a responsabilização de membros do Exército, da polícia e de civis por violações de direitos humanos cometidas entre 1980 e 1995.

No âmbito do SIDH, contudo, o Peru reconheceu sua responsabilidade internacional pelos fatos relacionados a esse caso $^{18}$, e a CtIDH teve oportunidade de discorrer sobre a incompatibilidade de leis de anistia com o parágrafo $1^{\circ} \mathrm{do}$ artigo $1^{\circ}$, o artigo $2^{\circ}{ }^{19}$, o artigo $8^{\circ}{ }^{20}$ e o artigo 25 da CADH e firmar um forte precedente. No parágrafo 143 da sentença de mérito, ficou estabelecido que:

A Corte julga necessário enfatizar que, à luz das obrigações gerais consagradas nos artigos 1.1 e 2 da Convenção

Americana, os Estados Partes têm o dever de tomar todo o tipo de medida para que ninguém seja privado da proteção

\footnotetext{
${ }^{17}$ Em julho de 1995, a Corte Superior de Justiça de Lima decidiu que essas duas leis de anistia não contrariavam a Constituição nem os tratados internacionais de direitos humanos e que, pelo princípio da separação de poderes, os juízes não poderiam condenar os envolvidos no massacre de Barrios Altos de aplicar uma lei adotada pelo Congresso.

${ }^{18}$ Inicialmente, porém, o Peru adotou postura pouco cooperativa com a CtIDH, devolvendo o caso e negando a própria competência dessa corte para julgá-lo. Nesse sentido, houve até mesmo uma resolução legislativa do Congresso peruano retirando a Declaração de Reconhecimento da Cláusula Facultativa de Jurisdição Obrigatória.

19 "Artigo 2. Dever de adotar disposições de direito interno. Se o exercício dos direitos e liberdades mencionados no artigo 1 ainda não estiver garantido por disposições legislativas ou de outra natureza, os Estados Partes comprometem-se a adotar, de acordo com as suas normas constitucionais e com as disposições desta Convenção, as medidas legislativas ou de outra natureza que forem necessárias para tornar efetivos tais direitos e liberdades".

20 "Artigo 8. Garantias judiciais. 1. Toda pessoa tem direito a ser ouvida, com as devidas garantias e dentro de um prazo razoável, por um juiz ou tribunal competente, independente e imparcial, estabelecido anteriormente por lei, na apuração de qualquer acusação penal formulada contra ela, ou para que se determinem seus direitos ou obrigações de natureza civil, trabalhista, fiscal ou de qualquer outra natureza”.
} 
judicial e do exercício do direito a um recurso simples e eficaz, nos termos dos artigos 8 e 25 da Convenção. É por isso que os Estados Partes da Convenção que adotem leis que tenham esse efeito, como são as leis de autoanistia, incorrem em violação dos artigos 8 e 25, em conformidade com os artigos 1.1 e 2 da Convenção. As leis de autoanistia levam ao desamparo das vítimas e à perpetuação da impunidade e por isso são manifestamente incompatíveis com a letra e o espírito Convenção Americana. Esse tipo de lei impede a identificação dos indivíduos responsáveis por violações a direitos humanos, já que obstrui a investigação e o acesso à justiça e impede que as vítimas e seus familiares conheçam a verdade e recebam a reparação correspondente (CtIDH, 2001, grifos nossos).

As considerações sobre a incompatibilidade da impunidade com a proteção de direitos humanos não se limitou ao caso específico das leis de autoanistia, como pode se ver no trecho abaixo:

Esta Corte considera que são inadmissíveis as disposições de anistia, de prescrição e o estabelecimento de excludentes de responsabilidade que pretendam impedir a investigação e sanção dos responsáveis por graves violações de direitos humanos, como a tortura, as execuções sumárias, extrajudiciais ou arbitrárias e os desaparecimentos forçados, todas elas proibidas por contrariar direitos inderrogáveis reconhecidos pelo Direito Internacional dos Direitos Humanos (CtIDH, 2001 grifos nossos).

Observa-se, portanto, que essa leitura da CtIDH sobre os artigos $8^{\circ}$ e 25 concluiu não apenas que a $\mathrm{CADH}$ inviabiliza qualquer mecanismo que crie óbices ao dever de investigar e punir os responsáveis por graves violações de direitos humanos, como também que desses dois disposi- 
tivos decorreria um direito à verdade, na medida em que ambos são instrumentos para o estabelecimento judicial dos fatos e das circunstâncias ligadas à violação de um direito fundamental.

Constatado o caráter violatório das leis de anista frente à $\mathrm{CADH}$, a CtIDH determinou que essas leis não possuíam efeitos jurídicos e, por esta razão, não poderiam constituir obstáculo para a investigação dos fatos do caso e a responsabilização dos indivíduos (CtIDH, 2001). Assim, no âmbito das reparações, a CtIDH estabeleceu a obrigação de se efetuar a investigação, publicizar seus resultados e sancionar responsáveis pelas violações de direitos humanos.

O Caso Barrios Altos é um marco na jurisprudência da CtIDH, constantemente citado pela enfática maneira como ele considera incompatível obstáculos que, embora legais, impeçam a responsabilização criminal de indivíduos que cometeram graves violações de direitos humanos (Aldana204 -Pindell, 2004, p.605-86; Binder, 2011, p.1203-30; Alessandri, 2005; Basch, 2007, p.195-229).

Independentemente do contexto doméstico, ficou sugerido no Caso Barrios Altos que qualquer tipo de anistia seria incompatível com os compromissos assumidos por meio da $\mathrm{CADH}$ e que, ao invés de polarizar justiça e verdade, a CtIDH passaria a defender a justiça penal como o meio por excelência de promoção do conhecimento da verdade. Apesar de o Caso Barrios Altos representar uma grande inovação no SIDH, sua principal novidade está na defesa da invalidade das leis de anistia perante as obrigações derivadas da CADH. Anos antes, a CIDH já começara a apontar a necessidade de se criminalizar os agentes responsáveis por violações de direitos humanos, como um mecanismo necessário para o ingresso na democracia. Paradigmática é a recomendação feita ao Chile, em 1974, de instaurar tribunais domésticos para agentes estatais responsáveis por violações de direitos humanos, quando essa prática não tinha 
acontecido sequer na Grécia, país que Sikkink identificou como pioneiro em uma das dimensões da cascata de justiça (2011, p.66). Mas até o Caso Barrios Altos, não existia um claro posicionamento do SIDH sobre as leis de anistia, já que a própria CIDH chegou a considerar que algumas anistias poderiam ser legítimas, como enunciou no informe anual de 1985-1986:

Uma questão difícil que as democracias recentes têm precisado confrontar é a da investigação de violações passadas de direitos humanos e a eventual sanção dos responsáveis por tais violações. A Comissão reconhece que este é um tema sensível e extremamente delicado, com o qual ela - assim como qualquer outro órgão internacional - pouco pode contribuir. Trata-se, portanto, de um assunto cuja resposta deve emanar dos próprios setores nacionais afetados e para o qual a urgência de reconciliação nacional e a pacificação social devem ser harmonizadas com as inevitáveis exigências de conhecimento da verdade e de justiça.

Considera a Comissão, portanto, que somente as instituições democráticas apropriadas - geralmente o Parlamento após discussão com a participação de todos os setores representativos, estão chamadas a determinar a procedência de uma anistia ou a sua extensão, sem que, por outro lado, possam ter validade jurídica as anistias decretadas previamente pelos próprios responsáveis pelas violações (CIDH, 1986, grifos nossos).

O Caso Barrios Altos e os casos subsequentes que lidavam com leis de anistia firmaram o entendimento de que responsabilidade criminal individual não é um tema reservado à esfera doméstica: pelo contrário, deve se adequar aos parâmetros internacionais, ainda que a escolha nacional (anistia, por exemplo) seja divergente e tomada por 
instâncias democráticas, como o Legislativo. Adicionalmente, a opção pelo conhecimento da verdade em detrimento da persecução criminal também não seria compatível com a CADH, como ficou explícito no Caso Zembrando Vélez e outros vs. Equador ${ }^{21}$, em que a CtIDH afirmou que as comissões de verdade não constituem uma alternativa ao processo penal e que a verdade por elas estabelecida deve ser vista de forma complementar àquela que deriva das instâncias judiciais:

A Corte considera que o estabelecimento de uma comissão da verdade, conforme o objeto, procedimento, estrutura e finalidade de seu mandato, pode contruibuir para a construção e preservação da memória histórica, o esclarecimento dos fatos e a determinação de responsabilidades institucionais, sociais e políticas em determinados períodos históricos de uma sociedade. As verdades históricas que se alcançam por meio deste mecanismo não devem ser entendidas como um substituto para o dever do Estado de assegurar a determinação judicial de responsabilidades individuais ou estatais pelos meios jurisdicionais correspondentes, nem para a determinação de responsablidade internacional que compete a este Tribunal. Tratam-se de determinações da verdade que são complementares entre si, pois têm cada uma sentido e alcance próprios, assim como potencialidades e limites particulares, que dependem do contexto em que surgem e dos casos e circunstâncias concretas que analisem (CtIDH, 2007a, grifos nossos).

A afirmação sobre a incompatibilidade de leis de anistia e os comprimissos assumidos no SIDH se seguiu por muitos anos depois do Caso Barrios Altos e abrangeu anistias

\footnotetext{
${ }^{21}$ O Caso Baldeón García tem ponderações similares, ver o parágrafo 167 de CtIDH (2006a).
} 
adotadas por países que tiveram processos de transição democrática bastante diversos. No Caso Almonacid Arellano (CtIDH, 2006c), a corte defendeu ser indiferente o tipo de anistia adotada na passagem para a democracia já que haveria uma regra de jus cogens - inderrogável, exceto por outra norma de mesmo status - proibindo tortura, desaparecimentos, exceções extrajudiciais e outros graves crimes e, assim, obrigando permanentemente a punição dos indivíduos que os cometam (Binder, 2011, p.1211). A vedação da anistia foi ressaltada diretamente em casos tratando da Guatemala (CtIDH, 2003b, 2004a, 2004c, 2007b), El Salvador (CtIDH, 2005a, 2011b), Suriname (2005b), Uruguai (CtIDH, 2011a) e Brasil (CtIDH, 2010d). Cabe destacar a sentença do Caso Gomes Lund, pois ele ilustra um posicionamento que corrobora a tese de Sikkink de que as decisões relativas à justiça de transição não são escolhas binárias a serem tomadas imediamente no momento da transição (Sikkink; Walling, 2010). Tendo sido o Brasil o único país da América Latina que não adotou nenhum dos principais mecanismos de justiça de transição - comissões de verdade ou julgamentos criminais -, a sentença da CtIDH foi a primeira grande vitória dos movimentos de direitos humanos que, depois de mais de 20 anos de regime democrático, buscam levar a "cascata de justiça" até o Brasil.

Como ilustram os casos de Brasil e Uruguai aqui citados, a discussão sobre leis de anistia não se restringiu aos anos de funcionamento do SIDH na década de 1990 e começo dos anos 2000. Com o fortalecimento do SIDH, esses casos, porém, passaram a ser julgados paralelamente com novos tipos de demandas, que não tinham vínculos imediatos com a transição para a democracia. Para finalizar a avaliação sobre a difusão da norma da responsabilidade criminal individual no SIDH, passaremos agora a analisar como o dever de persecução penal é trabalhado nesses demais casos. 


\section{A difusão da regra da responsabilidade criminal individual}

Comentando o processo de evolução do SIDH, Abramovich identifica um terceiro - e mais recente - momento da jurisprudência da CtIDH, ligado à inclusão de novos atores litigantes e à diversificação de sua agenda temática. Após muitos dos países da região terem consolidado regimes democráticos, melhorando sistemas eleitorais e respeitando a liberdade de imprensa, persistem sérias deficiências institucionais e graves níveis de desigualdade e exclusão social. Com isso, o SIDH começou a ser buscado para estabelecer princípios e parâmetros ligados a demandas por igualdade para grupos tradicionalmente marginalizados (Abramovich, 2009, p.10-2), de que é exemplo o conjunto de casos sobre o direito dos povos indígenas às suas terras tradicionais ${ }^{22}$.

Ao que parece, porém, a diversificação da agenda temática do SIDH não enfraqueceu a defesa da persecução cri208 minal individual como uma medida de direitos humanos, Pelo contrário. Depois do Caso Barrios Altos, a obrigação de os Estados tomarem todas as medidas necessárias para acabar com a impunidade foi constantemente reafirmada e a CtIDH identificou na garantia ao devido processo ${ }^{23}$ também um direito da vítima nos procedimentos criminais. A concepção do devido processo criminal como um direito da vítima ${ }^{24}$ implicou a interpretação de que caberia ao Estado assegurar a persecução penal e a punição dos indivíduos responsáveis pelas violações de direitos humanos como forma de reparação (Basch, 2007, p.206).

Portanto, existe uma dupla faceta na afirmação da CtIDH de que a ausência do cumprimento do dever de investigar e punir graves violações de direitos humanos é incom-

\footnotetext{
${ }^{22}$ Com destaque para os casos contra o Paraguai, ver CtIDH (2005c, 2006a, 2010a). ${ }^{23}$ Previsto, sobretudo, nas garantias dos artigos 8 e 25 da CADH.

${ }^{24}$ Quanto a isso também merece ser mencionado o Caso Castillo Paez (CtIDH, 1997a) e Aldana-Pindell, (2004, p.626).
} 
patível com a CADH. Enquanto, por um lado, a impunidade seria violatória aos direitos humanos por revelar falta de universalidade e objetividade na aplicação da lei (Carvalho Ramos, 2006, p.24); por outro, o processo penal também promoveria o direito de acesso à justiça ao indivíduo que teve seus direitos violados. Deste modo, haveria no entendimento da CtIDH um "novo papel da vítima no processo penal: o de exigir a punição dos autores das violações de Direitos Humanos sem qualquer exigência de prova de interesse material ou indenização na esfera cível" (Carvalho Ramos, 2006, p.40).

No processo de difusão da regra da persecução criminal individual, o Caso Bulacio vs. Argentina (CtIDH, 2003a) é bastante relevante por ter fixado os diversos parâmetros que apareciam difusos em casos anteriores já citados aqui: a obrigação de punir todas as violações de direitos humanos - não apenas as graves e sistemáticas - a rejeição a qualquer instituto jurídico - não só aqueles citados no Caso Barrios Altos - que sejam identificados como obstáculos para a punição e a prioridade aos direitos das vítimas se confrontados com os direitos do réu (Basch, 2007, p.207).

O Caso Bulacio trata da detenção ilegal de uma criança, Walter Bulacio, que em função de diversos ferimentos causados por agressões policiais faleceu ainda detido. O processo que levou à acusação de um agente de polícia, mas que não foi condenado em função da prescrição da ação penal (que já durava mais de 10 anos), ensejou a análise do respeito da Argentina aos artigos 8 e 25 da CADH. Foi nesse exercício interpretativo que a CtIDH expandiu a inafastabilidade da apuração penal de qualquer violação de direitos humanos, como se lê nos parágrafos 116 e 117 da sentença do Caso Bulacio:

Este Tribunal esclareceu que são inadmissíveis as disposições de prescrição ou qualquer obstáculo de direito interno 
mediante o qual se pretenda impedir a investigação e sanção dos responsáveis por violações de direitos humanos. A Corte considera que as obrigações gerais consagradas nos artigos 1.1 e 2 da Convenção Americana requerem dos Estados Partes a imediata adoção de providências de todo tipo para que ninguém seja subtraído do direito à proteção judicial, consagrada no artigo 25 da Convenção Americana. De acordo com as obrigações convencionais assumidas pelos Estados, nenhuma disposição ou instituto de direito interno, entre eles a prescrição, pode opor-se ao cumprimento das decisões da Corte relativas à investigação e sanção dos responsáveis pelas violações dos direitos humanos. De outra forma, os direitos consagrados na Convenção Americana estariam desprovidos de uma efetiva proteção (CtIDH, 2003a, grifos nossos) .

Para a CtIDH, o processo penal deve ser conduzido em consonância com essa intenção de satisfação dos direitos 210 da vítima e, nesse sentido, recursos do réu que tenham o objetivo de estender demasiadamente a duração do processo não podem ser tolerados pelos órgãos judiciais, os quais devem estar engajados em impedir que a apuração desses casos culmine em uma situação de impunidade.

Torna-se evidente a maneira como o olhar para a responsabilidade criminal "contaminou" todo o SIDH, nessas decisões que não estão tão preocupadas com a persecução criminal como uma necessidade para a consolidação da democracia, mas como um direito que não pode ser retirado da vítima em qualquer circunstância, ainda que prevista em lei (como a prescrição regular dos crimes).

Representativos de como a CtIDH incorporou ao modelo de responsabilidade internacional a defesa da persecução criminal doméstica são os casos ligados a demandas por reconhecimento de grupos minoritários, como aqueles relativos a direitos das mulheres. Nos três principais casos do CtIDH sobre essa temática (CtIDH, 2009, 2010b, 2010c), 
seguiu-se a interpretação da CIDH adotada no caso Maria da Penha (CIDH, 2001) e enfatizou-se a importância da persecução criminal dos agressores de mulheres como uma medida fundamental para assegurar os direitos deste grupo (Tramontana, 2011).

\section{Horizontes para a crítica da regra da persecução criminal individual no direito internacional dos direitos humanos}

A retomada da jurisprudência feita no item acima buscou indicar que a CtIDH tem consolidado em seu discurso a regra da responsabilidade criminal individual como uma das dimensões do direito internacional dos direitos humanos. Enquanto no primeiro caso analisado, Velásquez Rodríguez vs. Honduras, a CtIDH delineou as primeiras características do dever de investigar e punir violações de direitos humanos e não o interpretou como um direito da vítima $^{25}$, as decisões seguintes passaram a incluir a realização de processos penais como um elemento ligado à apuração da responsabilidade estatal e também às medidas de reparação para as vítimas.

Dessa forma, conforme a jurisprudência do SIDH se desenvolve, essa interpretação sobre o dever de investigar e punir tem se ampliado, fixando-o em, pelo menos, quatro eixos: (i) uma obrigação decorrente do parágrafo $1^{\circ}$ do artigo $1^{\circ}$ da CADH; (ii) uma medida que transforma o direito processual penal em um direito também da vítima de violações de direitos humanos; (iii) uma forma satisfação do direito à verdade; (iv) um instrumento de reparação e prevenção de novas violações da $\mathrm{CADH}$.

Apesar de pesquisas quantitativas demonstrarem que as obrigações de fazer e, sobretudo, o dever de investigar e punir, está entre as obrigações estabelecidas pela

\footnotetext{
${ }^{25} \mathrm{O}$ que é confirmado pelo fato de a obrigação de investigar e punir não ter aparecido entre as medidas de reparação.
} 
CtIDH que menos gozam de efetividade (Basch, 2010), são os precedentes relativos às leis de anistia os que alcançaram maior repercussão entre os Estados-partes da $\mathrm{OEA}^{26}$. Analisando a jurisprudência de diversos tribunais nacionais da América Latina, Ezequiel Malarino concluiu que existe uma forte tendência de os parâmetros estabelecidos pela CtIDH serem seguidos sobretudo nos seguintes $\operatorname{aspectos}^{27}$ : não admissão da prescrição; vedação de anistias, indultos e outros excludentes de responsabilidade; afastamento da coisa julgada; condenações por crimes contra a humanidade conforme tipificado em direito costumeiro (Malarino, 2007, p.209-210). Nesse sentido, o autor ainda observa que nas decisões nacionais o conceito mais invocado é o de "graves violações de direitos humanos" em lugar do de "crime contra a humanidade", mostrando uma clara adoção do vocabulário da CtIDH (Malarino, 2007, p.213).

212 Com a referência a Malarino, não se quer sugerir que somente da CtIDH emergiu a nova regra dos julgamentos de direitos humanos, mas sim que a apropriação dessa norma pela CtIDH tem levado a uma revisão de seu significado e que, nessa perspectiva, a regra da responsabilidade criminal individual, assim transformada, está novamente sendo difundida por diversos atores relevantes na região.

Justamente porque para Sikkink as discussões relativas à cascata de justiça não são apenas picuinhas ou preciosismos acadêmicos e, na verdade, têm sérias consequências para pessoas reais, para a democracia e para os direitos humanos (Sikkink, 2011, p.132), é interessante destacar

\footnotetext{
${ }^{26}$ Os impactos da interpretação da CtIDH sobre leis da anistia não se restringiram aos Estados que tiveram sua responsabilidade internacional estabelecida, por conta de um "spill-over effect" de casos como Barrios Altos (Binder, 2011, p.1222 et seq.).

${ }^{27}$ Naturalmente o autor observa que a aplicação dos precedentes da CtIDH goza de graus diferentes dependendo do país analisado. Argentina, Colômbia, Peru e Chile são os exemplos mais emblemáticos dos Estados que seguem as prescrições da CtIDH.
} 
alguns aspectos que foram incorporados pela CtIDH à regra da responsabilidade criminal individual e que podem suscitar questionamentos sobre as consequências (supostamente) positivas dessa cascata de justiça e que não foram identificadas pela autora.

A forma como a CtIDH tem defendido a prioridade do direito das vítimas em relação aos réus nos processos criminais fez com que, no Caso dos Irmãos Gómez Paquiyauri, a CtIDH levantasse ressalvas sobre o benefício de progressão de regime carcerário para dois dos envolvidos com as mortes dos meninos, por conta do sentimento de impunidade que poderia gerar (CtIDH, 2004b). Outro caso que chama atenção sobre os contornos que o dever de punir vem tomando é o das "Irmãs Serrano Cruz", no qual a sanção aos funcionários públicos ou particulares que eventualmente dilatassem indevidamente as investigações criminais deveria ser aplicada "com o maior rigor" das normas internas (CtIDH, 2004d).

Casos como estes levam a questionar se o terceiro pilar que diferencia esses julgamentos de direitos humanos dos julgamentos políticos realmente se sustenta: a questão do respeito aos direitos do acusado ${ }^{28}$. O que a jurisprudência do SIDH parece sugerir é que cada vez mais nenhum tipo de situação que leve a uma absolvição criminal em casos ligados a direitos protegidos na $\mathrm{CADH}$ serão aceitos, o que levanta dúvidas sobre a maneira como os direitos dos acusados de violações à integridade pessoal ${ }^{29}$ poderão ser realmente sustentados. Como se viu no Caso Bulacio, a defesa da regra da responsabilidade criminal individual não está limitada aos casos de violações graves e sistemáticas, mas a qualquer ofensa a direitos enunciados na $\mathrm{CADH}$.

\footnotetext{
${ }^{28}$ Sobretudo em relação ao devido processo legal.

${ }^{29}$ Protegida no artigo $5^{\circ}$ da $\mathrm{CADH}$.
} 
O amplo escopo da doutrina punitiva da CtIDH, que usa construções pouco delimitadas como a de crimes contra a humanidade e crimes previstos de forma costumeira, pode levar à emergência de um novo direito criminal do inimigo, que usa como referência a figura do violador de direitos humanos para afastar garantias legais dos acusados (Basch, 2007, p.213).

Esse tipo de incompatibilidade das persecuções criminais com os direitos humanos não é apurável pela metodologia ampla usada por Sikkink. O menoscabo que se opera ao direito do indivíduo condenado e que tem seus benefícios carcerários restringidos dificilmente é qualificado como uma violação de direitos humanos em registros mais globais e de amplo enfoque temático sobre a situação dos direitos humanos em um país. Além disso, a abordagem consequencialista que ela privilegia ignora por completo o quanto a persecução criminal pode ser intrinsicamente 214 incompatível com a proteção de direitos humanos quando a finalidade a que essa persecução almeja é o encarceramento do indivíduo condenado. Alguns pesquisadores têm mostrado o quanto a sanção penal baseada na pena de prisão ${ }^{30} \mathrm{e}$, portanto, com objetivos eminentemente repressores e socialmente excludentes, não pode ser compatível com o discurso dos direitos humanos que almeja à emancipação do homem (Singer, 2003; Pires, 2004).

$\mathrm{Na}$ criminologia, muitas pesquisas também apontam para a dificuldade de vincular a sanção penal à garantia de não repetição. Desde os trabalhos de Rusche e Kirchheimer (1939), defende-se que não existe uma relação de causalidade entre o endurecimento da punição e o decréscimo das taxas de criminalidade. Destarte, argumentar que os direi-

\footnotetext{
${ }^{30}$ Em diversas passagens do The Justice Cascade é possível depreender que para Sikkink punição criminal está ligada a pena de prisão, como logo no início do livro (Sikkink, 2011, p.13).
} 
tos humanos exigem normas penais ${ }^{31}$ em virtude do efeito dissuasório daquelas carece de fundamentação: a pena dificilmente pode ser vista como um instrumento eficaz para a efetivação dos direitos humanos porque sua aptidão para prevenir a violação de bens jurídicos ainda não conseguiu ser provada (Vaughan, 2000, p.73).

Conclui-se que a própria maneira como a norma da responsabilidade criminal individual tem se difundido exige que, para a análise do seu emprego, seja incorporada a avaliação dos elementos que lhe são agregados conforme é endossada por novos atores. Nesse processo que reconhece modificações a essa norma ela conforme se difunde, defendê-la não pode apenas se basear na refutação de antigas críticas, mas deve incorporar outros horizontes de problemas, como o do Estado policial, que comumente é mais abordado quando se fala do combate ao terrorismo ${ }^{32}$.

\section{Raquel da Cruz Lima}

é mestranda em direito internacional pela Faculdade de Direito da USP e bolsista da Fapesp.

\section{Referências bibliográficas}

ABRAMOVICH, V. 2009. "From massive violations to structural patterns: new approaches and classic tensions in the inter-american human rights system”. Sur, v.6, n.11, p.7-37.

ALDANA-PINDELL, R. 2004. "An emerging universality of justiciable victims' rights in the criminal process to curtail impunity for state-sponsored crimes". Human Rights Quartely, v.26, n.3, p.605-86.

ALESSANDRI, P. S. 2005. "La respuesta de la jurisprudencia de la corte interamericana a las diversas formas de impunidad en casos de graves violaciones de derechos humanos y sus consecuencias". In: CtIDH. $L a$

\footnotetext{
${ }^{31}$ Mais duras, já que não admitem nenhum tipo de limite em sua aplicação.

${ }^{32}$ Tema sobre o qual Sikkink tece considerações quando avalia a possibilidade de os agentes do governo Bush envolvidos nos casos de tortura serem julgados criminalmente.
} 
Corte Interamericana de Derechos Humanos: un cuarto de siglo: 1979-2004. San José, C.R.: CtIDH.

BASCH, F. F. 2007. "The doctrine of the inter-american court of human rights regarding state's duty to punish human rights violations and its dangers”. American University International Law Review, v.23, n.1, p.195-229.

et al. 2010. "The effectiveness of the Inter-American System of Human Rights Protection: a quantitative approach to its functioning and compliance with its decisions". Sur, v.7, n.12, p.9-35.

BINDER, C. 2011. "The prohibition of amnesties by the Inter-American Court of Human Rights". Germal Law Journal, v.12, n.5, p.1203-30.

CARVALHO RAMOS, A. 2006. "Mandados de criminalização no direito internacional dos direitos humanos: novos paradigmas da proteção das vítimas de violações de direitos humanos". Revista Brasileira de Ciências Criminais, n.62, p.9-55.

CIDH. 1986. Informe Anual (1985-1986), série L/V/II.68, doc. 8, rev.1, 26 set.

CtEDH. 1999. Case of Selmouni vs. France. Application n.25803/94, 28 jul. 2001. Maria da Penha Maia Fernandes vs. Brazil. Case 12.051, 16 abr.

CtIDH. 1982. Otros tratados. Objeto de la función consultiva de la Corte (Art. 64 Convención Americana sobre Derechos Humanos). Opinião consultiva, 24 set., série A, n.1. 1985. La colegiación obligatoria de periodistas (Arts. 13 y 29 Convención Americana sobre Derechos Humanos). Opinião consultiva, 13 nov., série A, n.5.

1986. Exigibilidad del derecho de rectificación o respuesta (Arts. 14.1, 1.1 y 2 Convención Americana sobre Derechos Humanos). Opinião consultiva, 29 ago., série A, n.7.

1987a. El hábeas corpus bajo suspensión de garantías (Arts. 27.2,

25.1 y 7.6 Convención Americana sobre Derechos Humanos). Opinião consultiva, 30 jan., série A, n.8.

1987b. Garantías judiciales en estados de emergencia (Arts. 27.2, 25 y 8 Convención Americana sobre Derechos Humanos). Opinião consultiva, 06 out., série A, n.9.

1988. Caso Velásquez Rodríguez vs. Honduras. Mérito. Sentença de 29 jul., série C, n.4.

. 1989a. Caso Godínez Cruz Vs. Honduras. Mérito. Sentença de 20 de jan., série C, n. 5 .

1989b. Caso Fairén Garbi y Solís Corrales Vs. Honduras. Mérito. Sentença de 15 de mar., série C, n. 6.

1989c. Caso Velásquez Rodríguez vs. Honduras. Reparações e custos. Sentença de 21 jul., série C, n.7. 
1997a. Caso Castillo Páez vs. Perú. Mérito. Sentença de 03 nov., série C, n.34.

1997b. Caso Suárez Rosero vs. Ecuador. Mérito. Sentença de 12 nov., série C, n.35.

1998. Caso de la "Panel Blanca" (Paniagua Morales y otros) vs. Guatemala. Mérito. Sentença de 08 mar., série C, n.37. 1999a. Caso de los "Niños de la Calle" (Villagrán Morales y otros) vs. Guatemala. Mérito. Sentença de 19 nov., série C, n.63. 2001. Caso Barrios Altos vs. Perú. Mérito. Sentença de 14 mar., série C, n.75.

2003a. Caso Bulacio vs. Argentina. Mérito, reparações e custos. Sentença de 18 set., série C, n.100. 2003b. Caso Myrna Mack Chang vs. Guatemala. Mérito. Reparações e custos. Sentença de 25 nov., série C, n.101. . 2004a. Caso Masacre Plan de Sánchez vs. Guatemala. Mérito. Sentença de 29 abr., série C, n.105.

. 2004b. Caso de los Hermanos Gómez Paquiyauri vs. Perú. Mérito, reparações e custos. Sentença de 08 jul., série C, n.110.

2004c. Caso Carpio Nicolle y otros vs. Guatemala. Mérito, reparações e custos. Sentença de 22 nov., série C, n.117.

2004d. Caso de las Hermanas Serrano Cruz vs. El Salvador. Exceções preliminares. Sentença de 23 nov., série C, n.118. 2005a. Caso de las Hermanas Serrano Cruz vs. El Salvador. Mérito, reparações e custos. Sentença de 01 mar., série C, n.120.

2005b. Caso de la Comunidad Moiwana vs. Surinam. Exceções preliminares, mérito, reparações e custos. Sentença de 15 jun., série C, n.124. 2005c. Caso Comunidad Indígena Yakye Axa vs. Paraguay. Mérito, reparações e custos. Sentença de 17 jun., série C, n.125.

. 2006a. Caso Comunidad Indígena Sawhoyamaxa vs. Paraguay. Mérito, reparações e custos. Sentença de 29 mar., série C, n.146. 2006b. Caso Baldeón García vs. Perú. Mérito, reparações e custos. Sentença de 06 abr., série C, n.147. 2006c. Caso Almonacid Arellano y otros vs. Chile. Exceções preliminares, mérito, reparações e custos. Sentença de 26 set., série C, n.154. 2007a. Caso Zambrano Vélez y otros vs. Ecuador. Mérito, reparações e custos. Sentença de 04 jul., série C, n.166. 2007b. Caso de la Masacre de las Dos Erres Vs. Guatemala. Exceção preliminar, mérito, reparações e custos. Sentença de 24 nov., série C, n.211. 
2009. Caso González y otras (“Campo Algodonero”) vs. México. Exceção preliminar, mérito, reparações e custos. Sentença de 16 nov., série C, n.205.

2010a. Caso Comunidad Indígena Xákmok Kásek vs. Paraguay. Mérito, reparações e custos. Sentença de 24 ago., série C, n.214.

2010b. Caso Fernández Ortega y otros vs. México. Exceção preliminar, mérito, reparações e custos. Sentença de 30 ago., série C, n.215. 2010c. Caso Rosendo Cantú y otra vs. México. Exceção preliminar, mérito, reparações e custos. Sentença de 31 ago., série C, n.216. 2010d. Caso Gomes Lund y otros (Guerrilha do Araguaia) vs. Brasil. Exceções preliminares, mérito, reparações e custos. Sentença de 24 nov., série C, n.219.

2011a. Caso Gelman Vs. Uruguay. Mérito e reparações. Sentença de 24 fev., série C, n.221.

2011b. Caso Contreras y otros vs. El Salvador. Mérito, reparações e custos. Sentença de ago., série C, n.232.

DULITZKY, A. 2006. "Federalismo y derechos humanos. El caso de la Convención Americana sobre Derechos Humanos y la República Argentina”. Anuario Mexicano de Derecho Internacional, n.6, p.199-249.

GARCIA ELORRIO, M. C. 2011. "Algunas consideraciones en torno a la naturaleza y alcance de la noción de diligencia debida en la jurisprudencia de la Corte Interamericana de Derecho Humanos". Disponível em <http://revistas.unc.edu.ar/index.php/recordip/article/view/286>. Acesso em 07/05/2012.

GAVRON, J. 2002. "Amnesties in the light of developments in international law and the establishment of the international criminal court". International and Comparative Quartely, v.51, n.1, p.91-117.

GONZÁLEZ, F. 2010. "The experience of the Inter-American Human Rights System”. Victoria University Wellington Law Review, v.40, n.1, p.103-126.

HANASHIRO, O. 2001. O sistema interamericano de proteção aos direitos humanos. São Paulo: Edusp.

LUTZ, E; SIKKINK, K. 2001. "The justice cascade: the evolution and impact of foreign human rights trials in Latin America", Chicago Journal of International Law, v. 2, n.1, p.1-34.

MALARINO, E. 2007. "Jurisprudencia latinoamericana sobre derecho penal internacional - um resumen". Lateinamerika Analyses, v.18, n.3, p.191-214.

NOLLKAEMPER, A. 2003. "Concurrence between individual responsibility and state responsibility in international law". International and Comparative Law Quartely, v. 52, n.3, p.615-40. 
PASQUALUCCI, J. 2003. The practice and procedure of the Inter-American Court of Human Rights. Cambridge, UK: CUP.

PIRES, A. 2004. "A racionalidade penal moderna, o público e os direitos humanos”. Novos Estudos, n.68, p.39-60.

RUSCHE, G; KIRCHHEIMER, O.1939. Punishment and Social Structure. New York; Morning Side Heights: Columbia University Press.

SIKKINK, K. 2011. The justice cascade: how human rights prosecutions are changing world politics. New York: W. W. Norton \& Co.

; Walling, C. B. 2010. "O impacto dos processos judiciais de direitos humanos na America Latina”. In: Reis, R. R. (org.). Política de direitos humanos. São Paulo: Hucitec.

SINGER, H. 2003. Discursos desconcertados: linchamentos, punições e direitos humanos. São Paulo: Humanitas.

TRAMONTANA, E. 2011. "Hacia la consolidacion de la perspectiva de género en el Sistema Interamericano: avances y desafios a la luz de la reciente jurisprudencia de la Corte de San José”, Revista IIDH, n.53, p.141-81.

VAUGHAN, B. 2000. "The civilizing process and the janus-face of modern punishment”. Theoretical Criminology, v.4, n.1, p.71-91. 


\section{A EMERGÊNCIA DA RESPONSABILIDADE CRIMINAL INDIVIDUAL NO SISTEMA INTERAMERICANO DE DIREITOS HUMANOS}

\section{RAQUEL DA CRUZ LIMA}

Resumo: Este artigo analisa a emergência e difusão da regra da responsabilidade criminal individual por violações de direitos humanos a partir da jurisprudência contenciosa da Corte Interamericana de Direitos Humanos. Tendo como referência as pesquisas de Kathryn Sikkink sobre justiça de transição, procura-se identificar a maneira como o Sistema Interamericano de Direitos Humanos vem expandindo o sentido da responsabilidade criminal individual e também sugerir a incompatibilidade com a proteção dos direitos humanos que esse novo modelo pode ter.

Palavras-chave: Dever de punir, Direitos humanos, Corte Interamericana de Direitos Humanos, Responsabilidade criminal.

\section{THE EMERGENCE OF INDIVIDUAL CRIMINAL ACCOUNTABILITY IN THE INTER=AMERICAN HUMAN RIGHTS SYSTEM}

Abstract: This paper analyzes the emergence and diffusion of the norm of individual criminal accountability for human rights 
violations from the perspective of the contentious jurisprudence of the Inter-American Human Rights Court. Taking as reference the research of Kathryn Sikkink on transitional justice, this paper seeks to identify how the Inter-American Human Rights System has been expanding the meaning of individual criminal accountability and also suggests the incompatibility with the protection of human rights that this new model may have.

Keywords: Duty to Punish, Human Rights, Inter-American Human Rights Court, Criminal Accountability 